\title{
Hospitalization for pulmonary embolism associated with antecedent testosterone or estrogen therapy in patients found to have familial and acquired thrombophilia
}

\author{
Marloe Prince ${ }^{*}$, Charles J. Glueck ${ }^{\dagger}$, Parth Shah ${ }^{\dagger}$, Ashwin Kumar ${ }^{\dagger}$, Michael Goldenberg ${ }^{\dagger}$, Matan Rothschild ${ }^{\dagger}$,
} Nasim Motayar ${ }^{\dagger}$, Vybhav Jetty $^{\dagger}$, Kevin Lee $^{\dagger}$ and Ping Wang ${ }^{\dagger}$

\begin{abstract}
Background: In patients hospitalized over a 4 year period for pulmonary embolism (PE), we assessed relationships of testosterone (TT) and estrogen therapy (ET) anteceding PE in patients found to have familial-acquired thrombophilia.

Methods: From 2011 through 2014, 347 patients were hospitalized in Cincinnati Mercy Hospitals with PE. Retrospective chart review was used to identify patients receiving $\Pi$ or ET before PE; coagulation studies were done prospectively if necessary.

Results: Preceding hospitalization for PE, 8 of 154 men (5\%) used T, and 24 of 193 women (12 \%) used ET. The median number of months from the initiation of TT or ET to development of PE was 7 months in men and 18 months in women. Of the 6 men having coagulation measures, all had $\geq 1$ thrombophilia, and of the 18 women having measures of coagulation, 16 had $\geq 1$ thrombophilia. The sensitivity of a previous history of thrombosis to predict PE was low, $25 \%$ (2/8 men), $4 \%$ (1/24 women).

Conclusions: Of 154 men hospitalized for PE, 8 (5\%) used TT, and of 193 women, 24 (12\%) used ET. Our data suggests that PE is an important complication of $T$ in men and $E T$ in women, in part reflecting an interaction between familial and acquired thrombophilia and exogenous hormone use.
\end{abstract}

Keywords: Thrombophilia, Testosterone, Estrogen, Pulmonary embolus

\section{Background}

When testosterone therapy (TT) is given to men or women with underlying familial or acquired thrombophilia, venous thromboembolism (VTE), deep venous thrombosis (DVT), pulmonary emboli (PE), ocular thrombosis, and osteonecrosis may occur [1-8]. In 67 recently reported cases of VTE, Glueck et al. [8] compared thrombophilia in 67 cases (59 men and 8 women) with thrombotic events after starting testosterone therapy versus 111 patient controls having unprovoked venous thrombotic events without TT. In the 67 patients,

\footnotetext{
* Correspondence: Marloe.prince@gmail.com

${ }^{\dagger}$ Equal contributors

From the Internal Medicine Residency Program, Cholesterol, Metabolism, and Thrombosis Center of the Jewish Hospital of Cincinnati, 2135 Dana Avenue, Suite 430, Cincinnati, OH 45207, USA
}

thrombosis (47 deep venous thrombosis-pulmonary embolism, 16 osteonecrosis, and 4 ocular thrombosis) occurred 6 months (median) after starting TT. Cases differed from controls for factor $\mathrm{V}$ Leiden heterozygosity (16 of the 67 [24\%] vs 13 [12\%] of the $111, P=.038$ ) and for lupus anticoagulant (9 [14\%] of the 64 vs 4 [4\%] of the $106, P=.019)$. After a first thrombotic event and continuing TT, 11 cases had a second thrombotic event, despite adequate anticoagulation, 6 of whom, still anticoagulated, had a third thrombosis. Screening for thrombophilia before starting TT should identify men and women at high risk for thrombotic events with an adverse risk-benefit ratio for TT. Glueck et al. [8] concluded that when TT is given to patients with familial and acquired thrombophilia, thrombosis may occur and recur in thrombophilic men despite anticoagulation. 
About $10 \%$ of patients with symptomatic DVTs develop severe post thrombotic syndrome within 5 years [9]. Despite adequate treatment, up to $25 \%$ of patients with symptomatic DVT-PE have recurrent VTE within 5 years [10]. Moreover, $25 \%$ of patients with VTE do not survive the first year after diagnosis [11].

In 596 men hospitalized for DVT-PE, we previously reported that 7 (1.2\%) had taken TT before and at time of their admission [3]. Of these 7 men, all 5 who had evaluation of thrombophilia-hypofibrinolysis were found to have previously undiagnosed procoagulants. Separately, we studied 147 men hospitalized for DVT-PE, finding 2 (1.4\%) with antecedent TT use [5]. Both men had previously undiagnosed thrombophilia [5]. Parallel to the TT-VTE relationship in men, estrogen-progestin birth control pills (BCP) and hormone replacement therapy (HRT) in women are associated with VTE [12-14], and the issue of screening for thrombophilia before prescription of BCP or HRT is contentious because of costeffectiveness issues [15].

In 347 patients (154 men, 193 women) hospitalized over a 4-year period for pulmonary embolism, we investigated testosterone and estrogen therapy (ET) use anteceding PE, and studies of procoagulants in TT and ET users.

\section{Methods}

\section{Patients}

\section{Ethics, consent}

The study was carried out following a protocol approved by the Jewish Hospital Institutional Review Board, with signed informed consent. No identifiable clinical data is presented.

From 2011 through 2014, using review of electronic medical records, 347 patients were hospitalized in Cincinnati Mercy Hospitals with PE. Only patients hospitalized for PE were studied. Retrospective chart review was used to document TT or ET use anteceding PE. We prospectively performed coagulation studies in those patients who used TT or ET, not having previous evaluation of thrombophilia-hypofibrinolysis.

Retrospectively, we reviewed coagulation data obtained at hospitalization for PE from electronic medical records in two other groups of patients not exposed to TT or ET, 78 with cancer associated with PE (17 had coagulation data), and 237 free of cancer (116 had coagulation data).

\section{Studies of thrombophilia and hypofibrinolysis}

PCR measures of the Factor V Leiden, prothrombin, MTHFR mutations and serologic measures of activated protein $C$ resistance $[16,17]$, antigenic proteins antithrombin III, C, total S, free S, homocysteine, factors VIII and XI $[18,19]$, the lupus anticoagulant, and anticardiolipin antibodies were carried out using established methods [20-22].

PCR measures of the 4G/5G mutation in the plasminogen activator inhibitor (Serpine1) gene [8, 23-25] were carried out using established methods [20-22]. Serologic studies of plasminogen activator inhibitor activity were not done.

\section{Statistical methods}

Within gender, users and non-users of ET/TT were compared by Fisher's exact test and by Wilcoxon tests. Thrombophilia in the 24 hormone users $(6$ men on TT, 18 women on ET) was compared to 116 cases (62 men, 54 women) with PE, not receiving TT or ET and free of cancer, and to 17 cases ( 9 men, 8 women) with cancer, not receiving TT or ET by Fisher's exact test.

\section{Results}

Preceding hospitalization for PE, of the 154 men and 193 women, 8 men ( $5 \%$ of men) used TT, 24 women (12\% of women) used ET (16 estrogen-progestin birth control pills $[\mathrm{BCP}], 6$ hormone replacement therapy [HRT], 2 progesterone), Fig. 1, Table 1. From the initiation of TT or ET to development of PE, the median time was 7 months in men and 18 months in women.

Median age in the 8 men was 56 , marginally $(p=.068)$ younger than in the 146 men not on TT (65). Median age in the 24 women with $\mathrm{PE}$ on ET was 38, younger than 169 women not taking ET $(69, p<.0001)$, Table 1 . Women taking ET with subsequent PE were less likely

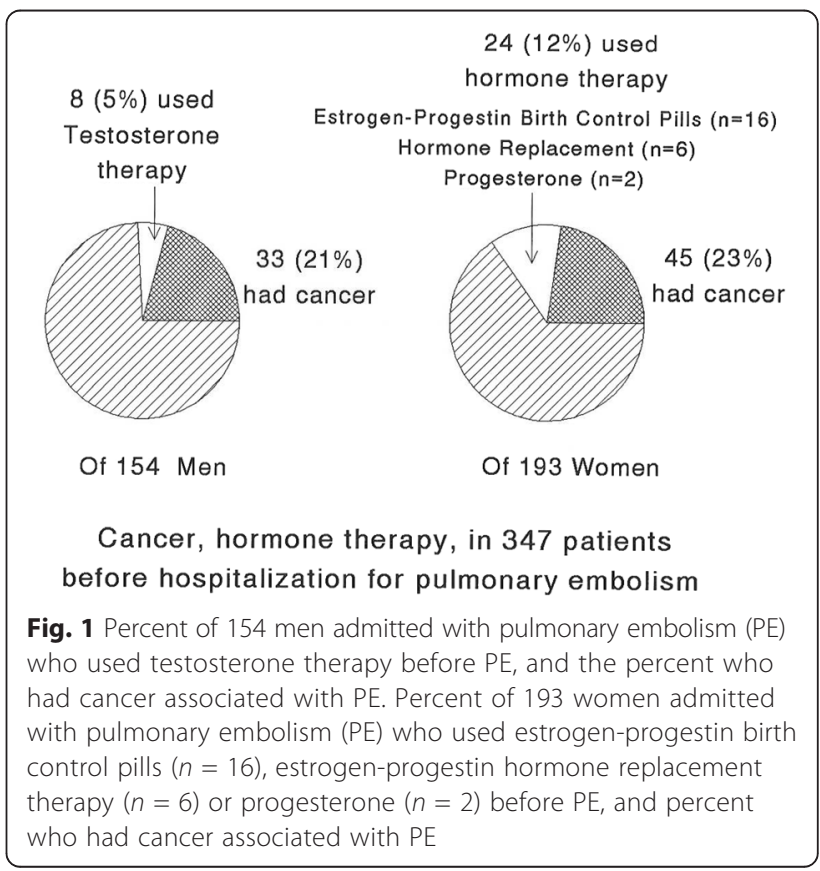


Table 1 Demographics in 347 pulmonary embolism patients (193 women, 154 men), by gender and by hormone use

\begin{tabular}{|c|c|c|c|}
\hline \multicolumn{4}{|l|}{ Women } \\
\hline & Hormone user, $n=24$ (12\%) & Non user, $n=169(88 \%)$ & all women $n=193(100 \%)$ \\
\hline Age (year) & $42 \pm 13$, median $38^{* * * *}$ & $66 \pm 17$, median 69 & $63 \pm 18$, median 65 \\
\hline Smoking & $7 / 24(29 \%)^{*}$ & $96 / 169(57 \%)$ & 103/193 (53\%) \\
\hline Hormone & BC pill 16 (67 \%) Estrogen 6 (25\%) Progesterone 2 (8 \%) & & \\
\hline Cancer & $0 / 24(0 \%)^{* *}$ & $45 / 169(27 \%)$ & 45/193 (23 \%) \\
\hline DM & $2 / 24(8 \%)$ & $42 / 169(25 \%)$ & 44/193 (23\%) \\
\hline Death & $0 / 24(0 \%)$ & $3 / 169(2 \%)$ & $3 / 193(2 \%)$ \\
\hline Thrombosis history & $1 / 24(4 \%)^{*}$ & 40/168 (24 \%), 1 missing & 41/193 (21\%) \\
\hline \multicolumn{4}{|l|}{ Men } \\
\hline & Hormone user, $n=8$ (5\%) & Non user $n=146$ (95\%) & All men $n=154(100 \%)$ \\
\hline Age (year) & $48 \pm 23$, median 56 & $63 \pm 17$, median 65 & $62 \pm 17$, median 64 \\
\hline Smoking & $5 / 8(63 \%)$ & 103/146 (71\%) & 108/154 (70 \%) \\
\hline Hormone & Testosterone & & \\
\hline Cancer & 0/8 (0 \%) & $33 / 146$ (23 \%) & $33 / 154$ (21 \%) \\
\hline DM & $2 / 8(25 \%)$ & $31 / 146$ (21 \%) & 33/154 (21 \%) \\
\hline Death & 0/8 (0 \%) & $2 / 146(1 \%)$ & 2/154 (1 \%) \\
\hline Thrombosis history & $2 / 8(25 \%)$ & $31 / 146(21 \%)$ & 33/154 (21 \%) \\
\hline
\end{tabular}

${ }^{*} p<.05,{ }^{* *} p<.01$, comparing hormone user vs non user in each gender by Fisher's exact test

**** $p<.0001$, comparing hormone user vs non user in each gender by Wilcoxon test

than women not taking ET to have cancer, and were less likely to have a previous thrombosis history (4\% vs 24 $\%, p<.05)$, Table 1 .

Of the 8 men using TT before their PE, 6 used TT gels, $50 \mathrm{mg} /$ day, and 2 had intra muscular TT $50 \mathrm{mg} /$ week. Of these 8 men, 5 (63\%) smoked, 2 had a previous history of thrombotic events, and 2 had type 2 diabetes, Table 1.

Coagulation evaluations were done in 6 of the 8 men with TT anteceding PE, Table 2 . All 6 had $\geq 1$ thrombophilia or hypofibrinolysis: 1 heterozygous for the G20210A prothrombin gene mutation, 1 homozygous for the 4G4G PAI-1 gene mutation, 1 with high factor VIII, 1 with high ACLA IgG, 3 with high homocysteine (1 of whom had MTHFR C677T homozygosity), 2 with low protein $C, 2$ with low protein $S$, and 2 with low free protein $\mathrm{S}$, Table 2. Two of 8 men had Klinefelters syndrome.

Of the 24 women taking ET before PE, 2 were diabetic, 1 had a previous history of thrombosis and 7 (29\%) smoked, Table 1.

Of the 24 women, 18 had measures of coagulation, and 16 (89\%) had $\geq 1$ thrombophilia (Table 3). Four women were $\mathrm{V}$ Leiden heterozygotes, 1 prothrombin

Table 2 Abnormal measures of thrombophilia and hypofibrinolysis in 8 men who using testosterone therapy before pulmonary embolism (6 men had coagulation measures)

\begin{tabular}{|c|c|c|c|c|c|c|c|c|c|}
\hline & PTG & MTHFR & PAIG & Homocysteine & Factor VIII & ACLA IgG & Pro C & PRO S & Free S \\
\hline Abnormal range & $\mathrm{TC} / \mathrm{TT}$ & $\pi$ & $4 \mathrm{G} 4 \mathrm{G}$ & Dated cut point ${ }^{a}$ & $>150 \%$ & Dated cut point ${ }^{b}$ & $<73 \%$ & $<63 \%$ & $<66 \%$ \\
\hline ID\# 1 & & & & 12.0 & & & 61 & & \\
\hline 2 & $\mathrm{TC}$ & & & & & 18.0 & & & 57 \\
\hline 4 & & & & & & & & 64 & \\
\hline 5 & & & $4 \mathrm{G} 4 \mathrm{G}$ & & 223 & & 47 & 49 & 43 \\
\hline 6 & & $\pi$ & & 17.3 & & & & & \\
\hline 7 & & & & 11.0 & & & & & \\
\hline
\end{tabular}


Table 3 Abnormal measures of thrombophilia and hypofibrinolysis in 24 women who used hormone replacement therapy on estrogen-progestin oral contraceptives before pulmonary embolism (18 women had coagulation measures)

\begin{tabular}{|c|c|c|c|c|c|c|c|c|c|c|}
\hline \multirow[b]{2}{*}{ Abnormal range } & FactorV & PTG & Factor VIII & FactorXI & ACLAlgG & ACLAlgM & Lupus anticoagulant & Pro S & Free S & Anti III \\
\hline & $\mathrm{TC} / \mathrm{TT}$ & $\mathrm{TC} / \mathrm{TT}$ & $>150 \%$ & $>150 \%$ & \multicolumn{2}{|c|}{ Dated cut point ${ }^{\mathrm{a}}$} & Y & $<63 \%$ & $<66 \%$ & $<80 \%$ \\
\hline ID\# 1 & & & & & & & & & & 78 \\
\hline 3 & & & & & & 20.0 & & & & \\
\hline \multicolumn{11}{|l|}{4} \\
\hline 5 & $\mathrm{TC}$ & & & & & & & 47 & & \\
\hline 6 & & & & & & & & & & 70 \\
\hline 8 & $\mathrm{TC}$ & & & & & & & & & \\
\hline 9 & & & & & & & Y & & & 71 \\
\hline 10 & & & 212 & & & & & & & \\
\hline 11 & & & & & & & Y & & & \\
\hline 12 & & & & & & & & & 61 & \\
\hline 13 & & & & & 16.0 & & & 59 & & \\
\hline \multicolumn{11}{|l|}{14} \\
\hline 15 & & & 301 & 151 & & 17.0 & & & 39 & \\
\hline 17 & & $\mathrm{TC}$ & & & & & & & & \\
\hline 18 & & & & & & & & 48 & & \\
\hline 22 & $\mathrm{TC}$ & & & & & & & & & \\
\hline 24 & $\mathrm{TC}$ & & & & & & & & & \\
\hline
\end{tabular}

adated cut point for IgG high: $\geq 23$ GPL (before 10/31/12); $\geq 15$ (after 11/1/12)

dated cut point for IgM high: $\geq 10$ MPL (before 4/30/12); $\geq 13$ (after 5/1/12)

gene heterozygote, 2 had high Factor VIII, 1 had high Factor XI, 2 were positive for the lupus anticoagulant, 3 had low protein S, 2 had low Free S, 3 had low antithrombin III, and 3 had high ACLA, Table 3.

Cancer was associated with PE in 78 patients, $22 \%$ of the cohort ( 45 women [ $23 \%$ of women], 33 men [21\% of men], Table 1, Fig. 1). None of the cancer patients took either TT or ET, Table 1 . Of the 33 men and 45 women with PE and concurrent cancer (Fig. 1), hospital based coagulation measures (Factor V Leiden, homocysteine, lupus anticoagulant, anticardiolipin antibody IgG and IgM, proteins $\mathrm{C}, \mathrm{S}$, and antithrombin III) were obtained in 17 (9 men, 8 women, Tables 4 and 5). Thrombophilia was rare in the 17 cancer patients with PE, with exception of homocysteine, which was high in $40 \%$ of cancer patients, marginally more common than in the 24 hormone users $(13 \%, p=.063)$, Tables 4 and 5 .

Of the 237 patients hospitalized with $\mathrm{PE}$, free of cancer and free of TT or ET supplementation, 116 had thrombophilia measures, Tables 4 and 5 . These 116 cases did

Table 4 Coagulation disorders in 24 cases ( 6 men [on testosterone] and 18 women [on estrogen]) who had testosterone/hormone therapy before PE, compared to 116 cases with PE but no hormone, no cancer (62 men, 54 women), and compared to 17 cancer cases ( 9 men, 8 women)

\begin{tabular}{|c|c|c|c|c|c|c|c|c|}
\hline & Factor V & PTG & MTHFR & PAIG & $\begin{array}{l}\text { Homocys- } \\
\text { teine } e^{a}\end{array}$ & $\begin{array}{l}\text { Lupus } \\
\text { anticoagulant }\end{array}$ & ACLA IgG & ACLA IgM \\
\hline Abnormal range & $\mathrm{TC}, \mathrm{TT}$ & $\mathrm{TC}, \mathrm{TT}$ & $\pi$ & $4 G 4 G$ & umol// & Positive & Dated $^{b}$ & Dated $^{c}$ \\
\hline $\begin{array}{l}\text { Hormone Cases } \\
(n=24,6 \text { men on } \pi, \\
18 \text { women on ET) }\end{array}$ & 4/24 (17 \%) & 2/24 (8 \%) & $1 / 24(4 \%)$ & $1 / 24(4 \%)$ & 3/24 (13\%) & 2/24 (8 \%) & $2 / 24$ (8 \%) & $2 / 24(8 \%)$ \\
\hline $\begin{array}{l}\text { PE_no hormone, no Cancer } \\
(n=116,62 \text { men, } 54 \text { women) }\end{array}$ & 15/105 (14 \%) & $\begin{array}{l}7 / 71 \\
(10 \%)\end{array}$ & & & $\begin{array}{l}18 / 43 \\
(42 \%) * *\end{array}$ & 17/68 (25 \%) & $1 / 61$ (2\%) & $5 / 58$ (9 \%) \\
\hline $\begin{array}{l}\text { Cancer ( } n=17,9 \text { men, } 8 \\
\text { women) }\end{array}$ & 0/15 (0 \%) & & & & 6/15 (40 \%) & 1/17 (6 \%) & 0/15 (0 \%) & $1 / 17$ (6 \%) \\
\hline
\end{tabular}

${ }^{* *} p<.025$, comparing with Hormone cases by Fisher's test

adated cut point for Homocysteine high: $\geq 15$ (11/15/08-12/2/14); $\geq 10.4$ (after 12/3/14)

${ }^{b}$ dated cut point for IgG high: $\geq 23 \mathrm{GPL}$ (before 10/31/12); $\geq 15$ (after 11/1/12)

'dated cut point for IgM high: $\geq 10 \mathrm{MPL}$ (before 4/30/12); $\geq 13$ (after 5/1/12) 
Table 5 Coagulation disorders in 24 cases ( 6 men [on testosterone] and 18 women [on estrogen]) who had testosterone/hormone therapy before PE, compared to 116 cases with PE but no hormone, no cancer (62 men, 54 women), and compared to 17 cancer cases (9 men, 8 women)

\begin{tabular}{|c|c|c|c|c|c|c|}
\hline & Factor VIII & Factor XI & Protein C & Protein S & Free $\mathrm{S}$ & Antithrombin III \\
\hline Abnormal range & $>150 \%$ & $>150 \%$ & $<73 \%$ & $<63 \%$ & $<66 \%$ & $<80$ \\
\hline Hormone Cases ( $n=24,6$ men on TT,18 women on ET) & $3 / 24(13 \%)$ & $1 / 23(4 \%)$ & $2 / 24(8 \%)$ & $5 / 24(21 \%)$ & $4 / 24(17 \%)$ & $3 / 24(13 \%)$ \\
\hline PE_no hormone, no Cancer ( $n=116,62$ men, 54 women) & & & $27 / 90(30 \%)^{*}$ & $8 / 77(10 \%)$ & 11/74 (15 \%) & $8 / 80(10 \%)$ \\
\hline Cancer ( $n=17,9$ men, 8 women) & & & $1 / 16(6 \%)$ & $1 / 16(6 \%)$ & & $1 / 14(7 \%)$ \\
\hline
\end{tabular}

${ }^{*} p<.05$, comparing with Hormone cases by Fisher's test

not differ ( $p>0.4$ ) from the 24 hormone using cases, except for high homocysteine ( $42 \%$ vs $13 \%, p<.025)$ and low protein C (30\% vs $8 \%, p<.05)$, Tables 4 and 5 .

\section{Discussion}

Increased risk of VTE in women using combined oral contraceptives has been known for at least 52 years [26], and is well recognized for hormone replacement therapy [27]. By comparison, the association of VTE in men [1] and women [4, 6] using TT has only recently been described, as of 2011 and 2013-2015 respectively [1-6, 8]. Previously, in 596 men hospitalized for DVT-PE, we reported that 7 (1.2\%) had taken TT before and at time of their admission [3], and all 5 men who had evaluation of thrombophiliahypofibrinolysis were found to have previously undiagnosed procoagulants. Separately, we studied 147 men hospitalized for DVT-PE, finding 2 (1.4 \%) with antecedent TT use, both of whom had previously undiagnosed thrombophilia [5].

In the current study, of 154 men hospitalized for PE, 8 (5 \%) used TT, and of 193 women, 24 (12\%) used ET. congruent with previous studies [26, 27]. Congruent with our previous reports $[3,5]$, all of the men with PE after TT in the current study were found to have familial-acquired thrombophilia, as were $16 / 18$ women (89 \%) with PE after ET. Thrombophilia in the 24 cases using TT and ET was comparable to that in 116 cases not using TT or ET. As in the current study, when TT or ET are given to patients with previously undiagnosed thrombophilia, thrombosis commonly occurs [8].

In the current study, thrombophilia was rare in patients whose PE was associated with cancer, in agreement with the report by Fiaz et al. [28] who reported that thrombophilia was more common among VTE patients without cancer than in those with cancer.

Health $[9,10]$ and cost [29-31] ramifications of a PE, either unprovoked or after TT or ET are significant. After PE, there is a high cost of hospitalization, rehospitalization, and post-PE care [29]. As summarized by Reitsma [32], “...the one-year mortality is $20 \%$ after a first VTE. Of the surviving patients, 15-25\% will experience a recurrent episode of VTE in the three years after the first event. Primary and secondary prevention is key to reducing death and disability from VTE."

Selective coagulation screening based on prior VTE history, if applied to our 347 patients hospitalized for $\mathrm{PE}$, had low sensitivity, and would have identified only $25 \%$ of men with PE on TT, and only $4 \%$ of women with PE on estrogen-progestin oral contraceptives-HRT. However, cost-effectiveness studies [33, 34] suggest that selective coagulation screening based on prior VTE history is more cost-effective than universal screening.

Limitations of our study include its retrospective observational nature, and a limited sample size of patients who took TT or ET and had coagulation screening. Our study is further limited by not having coagulation data on patients admitted with PE who died before coagulation measures were obtained.

\section{Conclusions}

Of 154 men hospitalized for PE, 8 (5\%) used TT, and of 193 women, 24 (12\%) used ET. Our data suggests that PE is an important complication of TT in men and $\mathrm{ET}$ in women, in part reflecting an interaction between familial and acquired thrombophilia and exogenous hormone use.

Our findings may have important clinical ramifications, because VTE risk is an important determinant of the benefit risk ratio of both TT and ET. In women, PE accounts for about one third of the incidence of potentially fatal VTE events associated with HRT [35], and HRT increases the risk of VTE by 2- to 3-fold [36].

Reitsma [32] has concluded that "...for primary prevention of VTE, genetic testing is not likely to play a role in the future." However, as the cost of screening for familial and acquired thrombophilias falls over time, with the development of multilocus genetic risk scores to improve classification, we believe that coagulation studies before starting TT, ET, and oral contraceptive therapy should be done as an approach to primary prevention of VTE, including at least PCR studies of the Factor $\mathrm{V}$ Leiden and Prothrombin gene mutations, Factors VIII and XI, homocysteine, and the lupus anticoagulant. 


\section{Availability of supporting data}

\section{All supporting data is available in SAS and Excel files from Ping Wang PhD (pxwang@mercy.com).}

\section{Abbreviations}

PE: Pulmonary embolism; TT: Testosterone therapy; ET: Estrogen therapy; VTE: Venous thromboembolism; DVT: Deep venous thrombosis; BCP: Birth control pills; HRT: Hormone replacement therapy; ACLA: Anticardiolipin antibodies.

\section{Competing interests}

The authors declare that they have no competing interests.

\section{Authors' contributions}

MP acquired data, drafted and revised manuscript and helped with coordination. CG designed the study, drafted and revised the manuscript as well as interpreted the data. PS acquired data and revised the manuscript. AK acquired data and revised the manuscript. MG acquired data and revised the manuscript. MR acquired data and revised the manuscript. NM acquired data and revised the manuscript. VJ acquired data and revised the manuscript. KL acquired data and revised the manuscript. PW analyzed and interpreted the data, provided statistical analysis and revised the manuscript. All authors read and approved the final manuscript.

\section{Authors' information}

MP is a PGY-2 MD at the Jewish hospital of Cincinnati, Ohio involved in many projects. CG is an MD and the medical director of the Cholesterol, Metabolism, and Thrombosis center of Jewish hospital. PS is a MD and current researcher at the Cholesterol, Metabolism, and Thrombosis center. AK is a current second year college student working with Dr Glueck. MG is a current second year college student working with Dr Glueck. MR is a PGY-2 MD at the Jewish hospital of Cincinnati, Ohio. NM is a PGY-2 MD at the Jewish hospital of Cincinnati, Ohio. VJ is a MD and current researcher at the Cholesterol, Metabolism, and Thrombosis center. KL is a PGY-2 MD at the Jewish hospital of Cincinnati, Ohio. PW is a PhD and statistician at the Cholesterol, Metabolism, and Thrombosis center.

\section{Acknowledgements}

No other individuals to acknowledge.

Received: 27 October 2015 Accepted: 27 February 2016

Published online: 08 March 2016

\section{References}

1. Glueck CJ, Goldenberg N, Budhani S, Lotner D, Abuchaibe C, Gowda M, et al. Thrombotic events after starting exogenous testosterone in men with previously undiagnosed familial thrombophilia. Transl Res. 2011;158:225-34.

2. Glueck CJ, Wang P. Testosterone therapy, thrombosis, thrombophilia, cardiovascular events. Metabolism. 2014:63:989-94.

3. Glueck CJ, Richardson-Royer C, Schultz R, Burger T, Bowe D, Padda J, et al. Testosterone therapy, thrombophilia-hypofibrinolysis, and hospitalization for deep venous thrombosis-pulmonary embolus: an exploratory, hypothesisgenerating study. Clin Appl Thromb Hemost. 2014;20:244-9.

4. Freedman J, Glueck CJ, Prince M, Riaz R, Wang P. Testosterone, thrombophilia, thrombosis. Transl Res. 2015;165:537-48.

5. Glueck CJ, Friedman J, Hafeez A, Hassan A, Wang P. Testosterone therapy, thrombophilia, and hospitalization for deep venous thrombosis-pulmonary embolus, an exploratory, hypothesis-generating study. Med Hypotheses. 2015;84:341-3

6. Glueck CJ, Bowe D, Valdez A, Wang P. Thrombosis in three postmenopausal women receiving testosterone therapy for low libido. Womens Health (Lond Engl). 2013;9:405-10.

7. Glueck CJ, Richardson-Royer C, Schultz R, Burger T, Labitue F, Riaz MK, et al. Testosterone, thrombophilia, and thrombosis. Clin Appl Thromb Hemost. 2014:20:22-30

8. Glueck CJ, Prince M, Patel N, Patel J, Shah P, Mehta N, et al. Thrombophilia in 67 Patients With Thrombotic Events After Starting Testosterone Therapy. Clin Appl Thromb Hemost. 2015.

9. Kearon C. Natural history of venous thromboembolism. Circulation. 2003; 107:122-30.
10. White $\mathrm{RH}$. The epidemiology of venous thromboembolism. Circulation. 2003;107:14-8.

11. Bertoletti L, Quenet S, Laporte S, Sahuquillo JC, Conget F, Pedrajas JM, et al. Pulmonary embolism and 3-month outcomes in 4036 patients with venous thromboembolism and chronic obstructive pulmonary disease: data from the RIETE registry. Respir Res. 2013;14:75.

12. Lidegaard O, Lokkegaard E, Svendsen AL, Agger C. Hormonal contraception and risk of venous thromboembolism: national follow-up study. BMJ. 2009:339:b2890.

13. Lidegaard O, Nielsen LH, Skovlund CW, Skjeldestad FE, Lokkegaard E. Risk of venous thromboembolism from use of oral contraceptives containing different progestogens and oestrogen doses: Danish cohort study, 2001-9. BMJ. 2011;343:d6423.

14. Davey DA. Update: estrogen and estrogen plus progestin therapy in the care of women at and after the menopause. Womens Health (Lond Engl). 2012;8:169-89.

15. Merriman L, Greaves M. Testing for thrombophilia: an evidence-based approach. Postgrad Med J. 2006:82:699-704.

16. Xin-Guang C, Yong-Qiang Z, Shu-Jie W, Lian-Kai F, Hua-Cong C. Prevalence of the Factor V E666D Mutation and Its Correlation With Activated Protein C Resistance in the Chinese Population. Clin Appl Thromb Hemost. 2015;21:480-3.

17. Zavala-Hernandez C, Hernandez-Zamora E, Martinez-Murillo C, Majluf-Cruz A Vela-Ojeda J, Garcia-Chavez J, et al. Risk Factors for Thrombosis Development in Mexican Patients. Ann Vasc Surg. 2015;29:1625-32.

18. Siegerink B, Maino A, Algra A, Rosendaal FR. Hypercoagulability and the risk of myocardial infarction and ischemic stroke in young women. J Thromb Haemost. 2015;13:1568-75.

19. Phillippe HM, Hornsby LB, Treadway S, Armstrong EM, Bellone JM. Inherited Thrombophilia. J Pharm Pract. 2014;27:227-33.

20. Glueck CJ, Bell H, Vadlamani L, Gupta A, Fontaine RN, Wang P, et al. Heritable thrombophilia and hypofibrinolysis. Possible causes of retinal vein occlusion. Arch Ophthalmol. 1999:117:43-9.

21. Glueck CJ, Freiberg RA, Fontaine RN, Tracy T, Wang P. Hypofibrinolysis, thrombophilia, osteonecrosis. Clin Orthop Relat Res. 2001:19-33.

22. Glueck CJ, Wang P, Bell H, Rangaraj V, Goldenberg N. Associations of thrombophilia, hypofibrinolysis, and retinal vein occlusion. Clin Appl Thromb Hemost. 2005;11:375-89.

23. Glueck CJ, Wang P. Ocular vascular thrombotic events: a diagnostic window to familial thrombophilia (compound factor $V$ Leiden and prothrombin gene heterozygosity) and thrombosis. Clin Appl Thromb Hemost. 2009;15:12-8.

24. Schenk JF, Stephan B, Zewinger S, Speer T, Pindur G. Comparison of the plasminogen activator inhibitor-1 4G/5G gene polymorphism in females with venous thromboembolism during pregnancy or spontaneous abortion. Clin Hemorheol Microcirc. 2008:39:329-32.

25. Jeon YJ, Kim YR, Lee BE, Choi YS, Kim JH, Shin JE, et al. Genetic association of five plasminogen activator inhibitor-1 (PAl-1) polymorphisms and idiopathic recurrent pregnancy loss in Korean women. Thromb Haemost. 2013:110:742-50.

26. Tyler ET. Oral contraception and venous thrombosis. JAMA. 1963;185:131-2.

27. Perez Gutthann S, Garcia Rodriguez LA, Castellsague J, Duque Oliart A. Hormone replacement therapy and risk of venous thromboembolism: population based case-control study. BMJ. 1997;314:796-800.

28. Faiz AS, Khan I, Beckman MG, Bockenstedt P, Heit JA, Kulkarni R, et al. Characteristics and Risk Factors of Cancer Associated Venous Thromboembolism. Thromb Res. 2015;136:535-41.

29. Fernandez MM, Hogue S, Preblick R, Kwong WJ. Review of the cost of venous thromboembolism. Clinicoecon Outcomes Res. 2015;7:451-62.

30. LaMori JC, Shoheiber O, Mody SH, Bookhart BK. Inpatient resource use and cost burden of deep vein thrombosis and pulmonary embolism in the United States. Clin Ther. 2015;37:62-70.

31. Raskob GE, Angchaisuksiri P, Blanco AN, Buller H, Gallus A, Hunt BJ, et al. Thrombosis: a major contributor to global disease burden. Arterioscler Thromb Vasc Biol. 2014:34:2363-71.

32. Reitsma PH. Genetics in thrombophilia. An update. Hamostaseologie. 2015; 35:47-51

33. Wu O, Robertson L, Twaddle S, Lowe G, Clark P, Walker I, et al. Screening for thrombophilia in high-risk situations: a meta-analysis and cost-effectiveness analysis. Br J Haematol. 2005;131:80-90.

34. Wu O, Robertson L, Twaddle S, Lowe GD, Clark P, Greaves M, et al. Screening for thrombophilia in high-risk situations: systematic review and 
cost-effectiveness analysis. The Thrombosis: Risk and Economic Assessment of Thrombophilia Screening (TREATS) study. Health Technol Assess. 2006;10: $1-110$.

35. Beral V, Banks E, Reeves G. Evidence from randomised trials on the longterm effects of hormone replacement therapy. Lancet. 2002;360:942-4.

36. Canonico M, Plu-Bureau G, Lowe GD, Scarabin PY. Hormone replacement therapy and risk of venous thromboembolism in postmenopausal women: systematic review and meta-analysis. BMJ. 2008;336:1227-31.

Submit your next manuscript to BioMed Central and we will help you at every step:

- We accept pre-submission inquiries

- Our selector tool helps you to find the most relevant journal

- We provide round the clock customer support

- Convenient online submission

- Thorough peer review

- Inclusion in PubMed and all major indexing services

- Maximum visibility for your research

Submit your manuscript at www.biomedcentral.com/submit 